\title{
PENTINGNYA MEMAHAMI KARAKTERISTIK SISWA DALAM PEMBELAJARAN BAHASA ARAB
}

\author{
M. Darkun \\ Pascasarjana Universitas Negeri Malang \\ Jl. Semarang No.5, Sumbersari, Kec. Lowokwaru, \\ Kota Malang, Jawa Timur 65145 \\ e-mail:muhammad.darkun@gmail.com

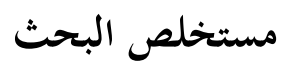

في عملية التعلم ، يُطلب من المعلم معرفة خصائص طلابه ، ولكن في بعض لابن

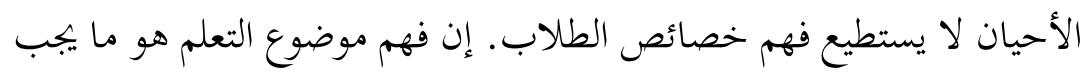

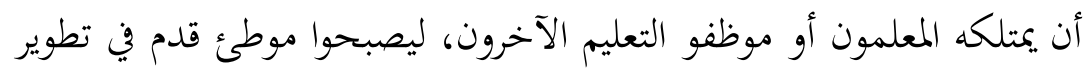
نماذج أو أساليب التعلم. الأهداف من كتابة هذه المقالة هو معرفة أهمية فهم خصائص الطلاب وتحقيق أهداف التعلم التي تم تحديدها، ومعرفة خصائص الطلاب لديهم دور مهم في عملية التعلم. تستخدم هذه الدراسة طرق البحث النوعي الوصفي. يتضمن هذا البحث بحثًا نصيًا أو دراسات نصية وهو كتابي

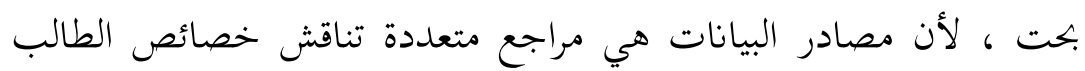
ونماذج تعلم الطلاب ، بالإضافة إلى المراجع المتعلقة بتعلم اللغة العربية. لأن نتائج هذه الدراسة في شكل تفسير الوصف المنهجي للكلمة نتيجة لفهم وتحليل موضوع البحث ، تشمل الدراسة البحث الوصفي.نتائج هذا البحث هي

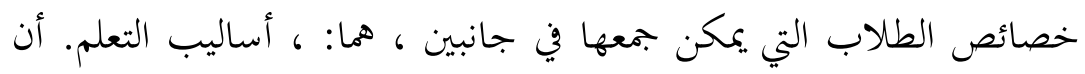
أساليب تعلم الأطفال بشكل عام تتعلم كأدوات بناء الشخصية وأفضل ذكاء للطلاب ، وهي: السمعية (التعلم عن طريق السمع) ، والبصرية (التعلم عن طريق المشاهدة) ، والحركية (التعلم بالممارسة). والتطبيق في تعلم كتاب اللغة العربية يتكيف مع نموذج / أسلوب تعلم الطلاب. الكلمات المفتاحية: خصائص الطلاب ، تعلم اللغة العربية 


\begin{abstract}
In the learning process a teacher is required to know the characteristics of his students, but sometimes he cannot understand the characteristics of students. Understanding of the subject of learning is what teachers or other education personnel must have, to be made a foothold in developing learning models or methods. The purpose of writing this article is to know the importance of understanding the characteristics of students and achieving the learning objectives that have been determined, and knowing the characteristics of students have an important role in the learning process. This study uses descriptive qualitative research methods. This research includes textual research or text studies and is purely biblical, because the data sources are various references that discuss student characteristics and student learning models, as well as references related to learning Arabic. Because the results of this study are in the form of an explanation of the systematic description of the word as a result of understanding and analysis of the object of research, the study includes descriptive research. The results of this study are the characteristics of students can be collected in two aspects, namely: learning styles. While children's learning styles in general are learning as character building tools and the best intelligence for students, namely: auditory (learning by hearing), visual (learning by seeing), and kinesthetic (learning by doing). And the application in learning Arabic Language writer adjusts to the model / learning style of students.
\end{abstract}

Keywords: Characteristics of Students, Learning Arabic

\title{
A. Pendahuluan
}

Banyak model pembelajaran yang digunakan untuk meningkatkan kualitas pendidikan namun banyak juga faktor yang menyebabkan kualitas pendidikan yang rendah salah satunya yaitu kegiatan belajar mengajar yang kurang bahkan tidak tanggap pada apa yang harus dilakukan oleh siswa. Supaya pembelajaran dapat berkualitas, perlunya dibuatkan dan dikembangkan berdasar pada kondisi anak didik sebagai sebuah subjek pembelajaran yang melakukan proses pembelajaran. Siswa merupakan seseorang yang memiliki keunikan sendiri dalam dirinya, dan seseorang itu mempunyai karakteristik berbeda. 
Salah satu teknik atau metode yang bisa membuat suasana kelas menjadi menyenangkan adalah dengan adanya keterampilan guru dalam mengelola kelas. Tentunya seorang guru yang baik adalah yang memahami kondisi siswa pada saat kegiatan belajar mengajar. Pengajar tersebut tidaklah hanya memaksakan kehendaknya saja untuk menyampaikan materi, namun juga mampu membawa kondisi yang menyenangkan dalam pembelajaran. ${ }^{1}$

Dalam dunia pendidikan seorang guru dituntut untuk mengetahui karakteristik siswanya. Hal tersebut yang wajib dipunya oleh pengajar ataupun tenaga kependidikaan lain, untuk menjadi suatu acuan dalam pengembangan model atau metode pembelajaran. Beberapa sistem pendidikan yang digunakan dalam proses pembelajaran yang menunjukan bahwa anak didik tak biasa ikut aktif pada proses pembelajaran didalam kelas, mereka bahkan cenderung pasif. Hal itu berakibat pada minimnya pemahaman mereka, pembelajaran menjadi tak bermakna, kurang bergairah dalam belajar dan kurangnya sentuhan pada kehidupan sosiokultural anak didik.

Menurut Degeng banyak upaya peningkatan kualitas pembelajaran telah dilakukan oleh para ilmuwan pembelajaran. Mereka mengklasifikasikan variabel-variabel yang menjadi perhatian, terutama bila dikaitkan dengan kegiatan dalam mengembangkan teori-teori dan prinsip-prinsip pembelajaran. Di antara para ilmuwan tersebut adalah Reigeluth dan Merrill. Mereka membuat klasifikasi ke dalam tiga variabel pembelajaran utama, yaitu: 1) kondisi pembelajaran, 2) metode pembelajaran, dan 3) hasil pembelajaran. ${ }^{2}$

\footnotetext{
${ }^{1}$ Ahmad Arifin, "Peranan Permainan Bahasa dalam Proses Kegiatan Belajar Mengajar Mata Pelajaran Bahasa Arab," An Nabighoh Jurnal Pendidikan dan Pembelajaran Bahasa Arab 19, no. 2 (2017), https://doi.org/10.32332/an-nabighoh.v19i2.1005.

${ }^{2}$ Reigeluth, C. M. 1983. Instructional Design: What is it and Why is it? dalam Charles Morgan Reigeluth, ed., Instructional Design Theories and Models: an Overview of Their Current Status (Hillsdale, N.J.: Lawrence Erlbaum Associates, 1983), h. 29; dan I Nyoman Sudana Degeng dan Nyoman Sudana, Ilmu Pengajaran Taksonomi Variabel (Jakarta: Depdikbud, 1989), h. 19.
} 
Tujuan dari penulisan artikel ini adalah untuk mengetahui pentingnya memahami karakteristik pebelajar dalam meningkatkan keberhasilan mengajar serta mencapai tujuan pembelajaran yang telah ditentukan, dan mengetahui karakteristik pebelajar mempunyai peran penting dalam proses pembelajaran.

Adapun harapan penulis bagi guru yaitu agar memiliki perhatian lebih terhadap karakteristik peserta didiknya, sehingga dapat membantu memudahkan dalam mengajar siswa dengan berbagai karakteristik yang berbeda-beda dan dalam kondisi berbeda juga. Sedangkan bagi lembaga pendidikan semoga dapat membantu dalam menentukan strategi pembelajaran yang akan digunakan pada suatu lembaga pendidikan yang didasarkan atas karakteristik siswa. Serta lembaga tersebut dapat membantu siswanya untuk belajar sesuai tujuan pembelajaran.

\section{B. Metode Penelitian}

Penelitian ini termasuk penelitian tekstual atau studi teks dan bersifat kepustakaan murni, karena sumber datanya adalah berbagai rujukan yang membahas tentang karakteristik siswa dan model pembelajaran siswa, serta rujukan yang berhubungan dengan pembelajaran Bahasa Arab. Karena hasil penelitian ini berupa penjelasan dari uraian kata secara sistematik sebagai hasil pemahaman dan analisis terhadap objek penelitian maka penelitian termasuk penelitian deskriptif. Sesuai dengan sifatnya penelitian menggunakan metode penelitian kualitatif deskriptif.

Pada penelitian ini, teknik pengumpulan data yang dipergunakan yaitu teknik dokumentasi. Prosedur pengumpulannya adalah membaca dan mengkaji sumber data yang berkaitan dengan karakteristik siswa dan model atau gaya belajar siswa, serta berkaitan dengan pembelajaran Bahasa Arab. 
Adapun teknik analisis datanya yaitu menggunakan analisis deskriptif yang menjelaskan serta mendeskriptifkan dari sumber data dan memaparkan dalam bentuk teks deskriptif tentang karakteristik siswa dan penerapan model belajar dalam pembelajaran Bahasa Arab. Mendeskriptifkan model pembelajaran Bahasa Arab sesuai gaya belajar auditori, visual dan kinestetik.

\section{Hasil dan Pembahasan}

\section{a) Karakteristik Pebelajar}

Antara anak didik satu dengan lainnya punya kemampuan yang berbeda-beda. Hal itu juga didasarkan pada lingkungan sosial tempat dia berasal. Jadi karakter anak didik itu dipengaruhi adanya kemampuan, lingkungan sosial dan juga pembawaan mereka masing-masing. Hal tersebut mempengaruhi pola perilaku dalam aktivitas yang dilakukan oleh anak didik di dalam sekolah ataupun di luar sekolah. Tujuan akhir dari aktivitas mereka tidak lain untuk pencapaian cita-cita mereka dengan bimbingan dari seorang guru yang mengajarnya.

Adapun supaya pembelajaran menjadi bermakna menurut Vygotsky diperlukan rancangan dan pengembangan yang berlandaskan pada kondisi anak didik sebagai subyek pembelajaran serta komunitas sosialkultural dimana siswa tersebut berada. ${ }^{3}$ Menurut Waidl hal penting yang harus dipahami yang berkaitan dengan siswa sebagai individu, bahwa siswa adalah manusia yang memiliki sejarah, makhluk dengan ciri keunikan (individualitas), selalu membutuhkan sosialisasi di antara mereka, memiliki keinginan untuk melakukan hubungan dengan alam sekitar, dan dengan kebebasannya mengolah pikir. Pemahaman akan

\footnotetext{
${ }^{3}$ C. Asri Budiningsih, "Karakteristik Siswa sebagai Pijakan dalam Penelitian dan Metode Pembelajaran," Jurnal Cakrawala Pendidikan 30, no. 1 (2011): h. 165, https://doi.org/10.21831/cp.v1i1.4198.
} 
siswa sebagai subjek belajar inilah yang harus dijadikan dasar dalam mengembangkan teori-teori maupun praksis-praksis pendidikan. Paulina Pannen mengemukakan bahwa dalam merancang pembelajaran jika dikaitkan dengan karakteristik budaya siswa, hasil belajar siswa akan meningkat. ${ }^{4}$

Reigeluth sebagai seorang ilmuwan pembelajaran, bahkan secara tegas menempatkan karakteristik siswa sebagai satu variabel yang paling berpengaruh dalam pengembangan strategi pengelolaan pembelajaran begitupun juga pakar-pakar pembelajaran (Banathy; Dick dan Carey,) menempatkan langkah analisis karakteristik siswa pada posisi yang amat penting sebelum langkah pemilihan dan pengembangan strategi pembelajaran. ${ }^{5}$ Semua ini menunjukkan bahwa model pembelajaran apapun yang dikembangkan atau strategi apapun yang dipilih untuk keperluan pembelajaran haruslah berpijak pada karakteristik perseorangan atau kelompok dari siapa yang belajar. Untuk mengembangkan strategi pembelajaran yang optimal terlebih dahulu guru perlu mengetahui karakteristik siswa sebagai pijakannya.

Karakteristik siswa yang dapat diidentifikasi sebagai faktor yang amat berpengaruh terhadap proses dan hasil belajar adalah kecerdasan, kemampuan awal, gaya kognitif, gaya belajar, motivasi, dan faktor sosialbudaya. Informasi tentang tingkat perkembangan kecerdasan siswa amat diperlukan sebagai pijakan dalam memilih komponen-komponen pembelajaran seperti tujuan pembelajaran, materi, media, strategi pembelajaran dan evaluasi. ${ }^{6}$

\footnotetext{
${ }^{4}$ A. Atmadi dan Yuliana Setyaningsih, Transformasi Pendidikan Memasuki Milenium Ketiga (Yogyakarta: Kanisius, 2004).

${ }^{5}$ Budiningsih, "Karakteristik Siswa sebagai Pijakan dalam Penelitian dan Metode Pembelajaran," h. 166.

${ }^{6}$ Thomas Armstrong, Multiple Intelligences in the Classroom (Alexandria: ASCD, 1994).
} 
Karakteristik siswa merupakan salah satu variabel dari kondisi pengajaran. Variable ini didefinisikan sebagai aspek-aspek atau kualitas perseorangan siswa. Aspek-aspek ini bisa berupa bakat, minat, sikap, motivasi belajar, gaya belajar, kemampuan berpikir, dan kemampuan awal (hasil belajar) yang telah dimilikinya. Karakteristik siswa akan sangat mempengaruhi dalam pemilihan strategi pengelolaan, yang berkaitan dengan bagaimana menata pengajaran, agar sesuai dengan karakteristik perseorangan siswa. ${ }^{7}$

Karakteristik siswa merupakan ciri atau sifat dan atribut yang melekat pada siswa yang menggambarkan kondisi siswa, misalnya kemampuan akademis yang telah dimiliki, gaya dan cara belajar serta kondisi sosial ekonomi. Karakteristik siswa merupakan keseluruhan pola perilaku dan kemampuan yang ada pada siswa sebagai hasil dari pembawaan dari lingkungan sosialnya sehingga menentukan pola aktivitas dalam meraih cita-citanya. Adapun hal yang mempunyai peranan penting dalam karakteristik siswa adalah gaya belajar.

\section{b) Gaya Belajar}

Suatu hal yang begitu penting dan sangat menjadi penentu untuk peserta didik saat menjalankan tugas belajar baik di rumah, di masyarakat, ataupun terutama saat di sekolah adalah gaya belajar. Siapa pun bisa belajar dengan lebih mudah, saat dia menemukan gaya belajar yang cocok bagi dirinya sendiri.

Oleh karenanya secara ringkas akan dijelaskan beberapa gaya belajar seseorang secara umum saat belajar sebagai suatu alat pembentukan karakter dan kecerdasan terbaik bagi siswa yaitu: Auditori (learning by hearing), visual (learning by seeing), dan kinestetik (learning by doing).

\footnotetext{
${ }^{7}$ Hamzah B. Uno, Orentasi Baru Dalam Psikologi Pembelajaran (Jakarta: Bumi
} Aksara, 2010), h. 211. 
1. Auditori

Gaya belajar auditori yaitu belajar dengan gaya mendengarkan guru yang mengajarkan suatu pelajaran. Adapun ciri-ciri seseorang dengan gaya belajar ini adalah seseorang sangat suka belajar melalui ceramah, diskusi, dan pembacaan pelajaran dengan jelas dan suara keras. Gaya belajar auditori merupakan kecenderungan untuk mempelajari materi pelajaran melalui indera pendengaran. Karakteristik model belajar seperti ini benar-benar menempatkan pendengaran sebagai alat utama menyerap informasi atau pengetahuan. ${ }^{8}$

Dijelaskan dalam Sharon E. Smaldino tentang karakteristik model pembelajaran auditori bagi siswa adalah sebagai berikut:

a. Perhatianya mudah terpecah.

b. Berbicara dengan pola berirama.

c. Belajar dengan cara mendengarkan, menggerakkan bibir/ bersuara.

d. Berdialog secara internal atau eksternal. ${ }^{9}$

2. Visual

Visual adalah strategi belajar dengan menggunakan indera penglihatan. Anak yang belajar dengan gaya belajar ini dapat belajar serta mengingat dengan baik jika proses pembelajaran itu dengan melihat gambar, peta, tabel, infokus, serta materi pelajaran secara langsung. Gaya belajar visual merupakan kecenderungan untuk mempelajari pengetahuan dan keterampilan melalui indera penglihatan. Gaya belajar seperti ini menjelaskan bahwa kita harus melihat dulu buktinya untuk kemudian bisa mempercayainya. ${ }^{10}$

\footnotetext{
${ }^{8}$ Benny Agus Pribadi, Model Desain Sistem Pembelajaran (Jakarta: Dian Rakyat, 2009).

${ }^{9}$ Sharon E. Smaldino, Deborah L Lowther, dan James D. Russell, Instructional Technology \& Media for Learning (Teknologi Pembelajaran dan Media untuk Belajar), trans. oleh Arif Rahman (Jakarta: Kencana Prenada Media Group, 2011), h. 72.

${ }^{10}$ Pribadi, Model Desain Sistem Pembelajaran.
} 
Selanjutnya Sharon E. Smaldino juga menjelaskan karakteristik siswa yang menggunakan model pembelajaran visual sebagai berikut:

a. Menyediakan acuan bagi gagasan.

b. Membuat gagasan abstrak menjadi konkret.

c. Memotivasi para pembelajar yang lain.

d. Mengarahkan perhatian.

e. Mengulangi informasi dalam format-format yang berbeda.

f. Mengingatkan kembali pada pelajaran sebelumnya.

g. Mengurangi usaha belajar. ${ }^{11}$

3. Kinestetik

Gaya belajar kinestetik merupakan kecenderungan melakukan proses belajar sambil melakukan aktifitas. Dalam gaya belajar ini kita harus menyentuh sesuatu yang memberikan informasi tertentu agar kita bisa mengingatnya. Ada beberapa karakteristik model belajar seperti ini yang tak semua orang bisa melakukannya, sebagai berikut: menempatkan tangan sebagai alat informasi utama agar kita bisa terus mengingatnya, hanya dengan memegang kita bisa menyerap informasinya tanpa harus membaca penjelasannya, termasuk orang yang tidak bisa/tahan duduk terlalu lama untuk mendengarkan pelajaran, merasa bisa belajar lebih baik apabila disertai dengan kegiatan fisik, orang yang memiliki gaya belajar ini memiliki kemampuan mengkoordinasi sebuah tim dan kemampuan mengendalikan gerak tubuh (athletic ability). ${ }^{12}$

Bagi seseorang yang punya karakteristik tersebut pendekatan belajar yang memungkinkan dapat dilaksanakan yaitu belajar

${ }^{11}$ Smaldino, Lowther, dan Russell, Instructional Technology \& Media for Learning (Teknologi Pembelajaran dan Media untuk Belajar), h. 72.

12 Pribadi, Model Desain Sistem Pembelajaran. 
berdasarkan pengalaman, yakni menggunkan model alat peraga, beraktifitas pada laboratorium ataupun belajar sembari bermain.

Dalam bukunya Louise B. Russell yang diterjemahkan oleh M. Irfan Zakkie bahwa ciri-ciri anak yang menggunakan model pembelajaran kinestetik adalah:

a. Ketika termenung untuk berpikir maka matanya akan menatap ke bawah.

b. Ketika berbicara dia akan berbicara dan bergerak lebih cepat.

c. Memanipulasi dawai suaranya seperti otot-otot yang lain.

d. Meninggikan dan merendahkan suaranya ketika mengubah nada suaranya untuk memberi efek emosional. ${ }^{13}$

\section{c) Pembelajaran Bahasa Arab}

Pada dasarnya semua proses pendidikan yang dilakukan adalah untuk mencapai tujuan pembelajaran yang ditentukan, dalam pembelajaran Bahasa Arab ada beberapa aspek yang harus dinilai dalam prosesnya, ada empat kemampuan yang harus ada dalam proses pembelajaran Bahasa Arab yaitu : Kemampuan menyimak, kemampuan berbicara, kemampuan membaca, dan kemampuan menulis.

1. Keterampilan Menyimak (Istima')

Sebagaimana dijelaskan dalam Abdurrahman bin Ibrahim alFauzan tentang tujuan keterampilan menyimak dalam pembelajaran bahasa Arab diantaranya peserta didik dapat:

a) Mengenal bunyi berbahasa Arab serta mengenal perbedaannya.

b) Mengenal bunyi baris yang dibaca panjang dan yang dibaca pendek.

c) Menangkap ide pokok dari cerita yang disimak.

d) Memahami pembicaraan berbahasa Arab.

${ }^{13}$ Louise B. Russell, The Accelerated Learning Fieldbook (Panduan Pembelajaran Cepat), trans. oleh M. Irfan Zakkie (Bandung: Nusa Media, 2011), h. 45. 
e) Membedakan antara ide primer dan yang sekunder.

f) Mengenal huruf yang dibaca double dan baris double.

g) Menyimpulkan dari pembicaraan yang disampaikan. ${ }^{14}$

2. Keterampilan Bercakap (Kalam)

Dijelaskan dalam Rusydi Ahmad Thu'aimah tujuan keterampilan berbicara dalam pembelajaran bahasa Arab, peserta didik dapat:

a) Menumbuhkan kemampuan pada keterampilan bercakap bagi peserta didik secara baik dan benar.

b) Menumbuhkan kekayaan bahasa yang peserta didik miliki.

c) Memfungsikan pengetahuan bahasa dari segi mufradat dan susunan kalimat, memicunya untuk maju dan sanggup mereproduksinya.

d) Menumbuhkan kemampuan siswa dalam membuat/ mencipta pada situasi dan kondisi yang diungkapkan dengan bahasa Arab.

e) Memicu peserta didik untuk selalu berlatih berbahasa Arab.

f) Memahami setiap komunikasi dan terlatih berkomunikasi.

g) Termotivasi untuk berkomunikasi di depan teman-temannya dan tidak takut salah dalam pengucapan. ${ }^{15}$

3. Keterampilan Membaca (Qira'ah)

Dijelaskan dalam Rusydi Ahmad Tho'aimah tujuan keterampilan Qira'ah adalah:

a) Qira'ah merupakan keterampilan dasar pertama dari keterampilan dasar yang tiga yaitu membaca, menulis, dan berhitung.

b) Pendidikan berlangsung terus menerus dan belajar sepanjang hayat. Oleh karena nya membaca merupakan kebutuhan pokok manusia baik secara kuantitas maupun kualitas pada aspek membaca.

${ }^{14}$ Abdur Rahman bin Ibrahim Al-Fauzan, Durus Ad-Daurat At-Tadribiyyah li Mu'allimiyi Al-Lughoh Al-'Arabiyah li Ghairi Nathiqina biha (Al-Janibi An-Nazhari) (Mu'assasah Waqfi Islami, 1425), h. 32-33.

${ }^{15}$ Al-Fauzan, h. 165-166. 
c) Membaca dengan pemahaman yang luas guna memperoleh informasi yang luas pula. Dengan keterampilan membaca, peserta didik memungkinkan mengkaji materi-materi berbahasa Arab.

d) Dengan keterampilan membaca yang dimiliki siswa memungkinkan mereka mencapai tujuan-tujuan praktis belajar bahasa Arab. Seperti memahami budaya, ekonomi, politik dan lain sebagainya. ${ }^{16}$

4. Keterampilan Menulis (Kitabah)

Dijelaskan dalam Rusydi Ahmad Tho'aimah tujuan Pembelajaran kitabah:

a) Memotivasi siswa untuk menulis bentuk lambang-lambang bahasa serta menimbulkan rasa percaya dan menghilangkan ketegangan.

b) Dalam pembelajarannya didukung dengan teknik penuturan huruf, kata dan kalimat. Sehingga peserta didik dapat menirukannya dan menulis dengan apa yang mereka dengar.

c) Peserta didik terlatih dan sudah mengenal pengucapan kata-kata. Sebab menulis merupakan aktivitas menyeluruh dalam penguasaan keterampilan bahasa sehingga peserta didik dapat membedakan bunyi lambang yang didengarnya. ${ }^{17}$

\section{d) Penerapan Model atau Gaya Belajar Siswa dalam Pembelajaran Bahasa Arab}

Pada bahasan kali ini penulis mencoba untuk menghubungkan antara aspek-aspek keterampilan bahasa Arab dengan gaya belajar siswa secara aplikatif. Untuk menerapkan gaya belajar siswa yang berbeda tidaklah mudah bagi semua guru, namun semua itu bisa kita pahami dengan menyesuaikan kurikulum yang berlaku. Dalam setiap mata pelajaran pasti

${ }^{16}$ Rushdi Ahmad Tu'aymah, Ta'lim al- Arabiyah li Ghayr An-Nathiqin biha: Manahijuhu wa Asalibuh (Maroko: ISESCO (Islamic Educational, Scientific and Cultural Organization), 1989), h. 176.

${ }^{17}$ Tu'aymah, h. 177-178. 
ada Rencana Pelaksanaan Pembelajaran (RPP), dalam hal ini semua guru dituntut untuk menyesuaikan metode maupun model pembelajaran dengan RPP tersebut, secara umum RPP yang digunakan mempunyai langkah-langkah pembelajaran yang sama meliputi: Pendahuluan, Kegiatan Inti, dan Penutup.

Untuk menerapkan model/gaya belajar sesuai karakteristik siswa maka harus menyesuaikan sesuai langkah-langkah pembelajaran yang tersebut yaitu:

1. Pendahuluan

Dalam kegiatan pendahuluan seorang guru harus memulai dengan memotivasi siswa agar proses pembelajaran yang akan dilaksanakan bisa diikuti oleh siswa dengan keadaan yang senang dan menerima apa yang akan dipelajari, dengan cara memberi arahan atau alur pembelajaran yang akan dilakukan, sehingga siswa mempunyai bayangan atau gambaran apa yang akan dilakukan.

2. Kegiatan Inti

Kegiatan inti merupakan kegiatan eksplorasi dan elaborasi, dalam kegiatan inti seorang pengajar menunjukkan siswa untuk aktif pada proses belajar secara mandiri, menyenangkan, relevan dan melibatkan panca indera siswa yang sesuai model/gaya belajar mereka masingmasing. Disini seorang guru bisa menerapkan model/gaya belajar berbasis audio, visual dan kinestetik.

1) Penerapan Gaya Belajar Audio

Seperti yang dijelaskan di atas gaya belajar auditori merupakan kecenderungan untuk mempelajari materi pelajaran melalui indera pendengaran. Maka dalam penerapanya harus berhubungan dengan indera pendengaran, adapun langkah-langkahnya sebagai berikut:

a) Guru menggunakan variasi vokal dalam mengajar. 
b) Agar pembelajaran lebih menarik guru bisa menghubungkan dengan beberapa lagu dalam pembelajaran.

c) Guru membuat suasana yang tenang dalam pembelajaran agar pendengaran lebih fokus.

d) Menerangkan materi pembelajaran dengan suara yang lantang jelas dan mudah di pahami.

e) Guru menanyakan kata-kata yang sulit dan menjelaskan artinya.

2) Penerapan Gaya Belajar Visual

Seperti yang dijelaskan di atas gaya belajar visual merupakan kecenderungan untuk mempelajari pengetahuan dan keterampilan melalui indera penglihatan, adapun langkah-langkahnya sebagai berikut:

a) Guru menggunakan materi visual seperti gambar-gambar yang berkaitan dengan tema mata pelajaran Bahasa Arab yang ditempel di sekeliling dinding atau diperlihatkan satu persatu.

b) Guru menggunakan aneka warna gambar agar lebih menarik.

c) Siswa dipersilahkan untuk melihat gambar dan menyebutkan apa yang ada sesuai gambar dengan Bahasa Arab.

d) Guru meminta siswa untuk mengilustrasikan ide-idenya dalam bentuk gambar.

3) Penerapan gaya Kinestetik

Dijelaskan dalam Pribadi diatas gaya belajar kinestetik merupakan kecenderungan melakukan proses belajar sambil melakukan aktifitas. Adapun langkah-langkahnya adalah:

a) Guru menggunakan alat bantu mengajar agar menumbuhkan rasa ingin tahu siswa.

b) Guru membuat gerakan yang berkaitan dengan materi pembelajaran Bahasa Arab. 
c) Siswa diminta untuk menebak gerakan yang di perlihatkan.

d) Siswa membuat kelompok untuk menampilkan gerakan yang telah ditentukan sesuai materi, dan kelompok lain menebaknya.

e) Guru berani memberi kebebasan bergerak dalam pembelajaran, namun gerakan yang tidak mengganggu proses pembelajaran.

\section{Penutup}

Penutup merupakan kegiatan terakhir dalam pembelajaran, dalam penutupan guru harus mengulang kembali apa yang telah diajarkan dengan ringkas, kemudian menguatkan kembali isi materi pembelajarn, serta memberikan tugas yang tidak memberatkan agar siswa senang dengan adanya tugas. Tidak lupa setiap akhir dari pembelajaran di akhiri dengan doa penutup.

\section{Simpulan}

Setiap anak didik memiliki karakteristik, yang hal itu termasuk suatu variabel dari kondisi pembelajaran. Variabel tersebut diartikan sebagai suatu aspek ataupun kualitas individu tiap anak didik. Karakteristik anak didik akan begitu berpengaruh dalam pemilihan strategi pembelajaran yang bertujuan kesesuaiannya dengan individu masing-masing anak didik. Karakteristik anak didik adalah keseluruhan pola kelakuan dan kemampuan yang ada pada anak didik sebagai hasil pembawaan dari lingkungan sosialnya. Adapun beberapa hal yang mempunyai peranan penting dalam karakteristik siswa adalah gaya belajar siswa serta penerapannya dalam penyusunan langkah-langkah pembelajaran. 


\section{Daftar Pustaka}

Al-Fauzan, Abdur Rahman bin Ibrahim. Durus Ad-Daurat At-Tadribiyyah li Mu'allimiyi Al-Lughoh Al-'Arabiyah li Ghairi Nathiqina biha (AlJanibi An-Nazhari). Mu'assasah Waqfi Islami, 1425.

Arifin, Ahmad. "Peranan Permainan Bahasa dalam Proses Kegiatan Belajar Mengajar Mata Pelajaran Bahasa Arab." An Nabighoh Jurnal Pendidikan dan Pembelajaran Bahasa Arab 19, no. 2 (2017). https://doi.org/10.32332/an-nabighoh.v19i2.1005.

Armstrong, Thomas. Multiple Intelligences in the Classroom. Alexandria: ASCD, 1994.

Atmadi, A., dan Yuliana Setyaningsih. Transformasi Pendidikan Memasuki Milenium Ketiga. Yogyakarta: Kanisius, 2004.

Budiningsih, C. Asri. "Karakteristik Siswa sebagai Pijakan dalam Penelitian dan Metode Pembelajaran." Jurnal Cakrawala Pendidikan 30, no. 1 (2011). https://doi.org/10.21831/cp.v1i1.4198.

Degeng, I Nyoman Sudana, dan Nyoman Sudana. Ilmu Pengajaran Taksonomi Variabel. Jakarta: Depdikbud, 1989.

Pribadi, Benny Agus. Model Desain Sistem Pembelajaran. Jakarta: Dian Rakyat, 2009.

Reigeluth, Charles Morgan, ed. Instructional Design Theories and Models: an Overview of Their Current Status. Hillsdale, N.J.: Lawrence Erlbaum Associates, 1983.

Russell, Louise B. The Accelerated Learning Fieldbook (Panduan Pembelajaran Cepat). Diterjemahkan oleh M. Irfan Zakkie. Bandung: Nusa Media, 2011.

Smaldino, Sharon E., Deborah L Lowther, dan James D. Russell. Instructional Technology \& Media for Learning (Teknologi Pembelajaran dan Media untuk Belajar). Diterjemahkan oleh Arif Rahman. Jakarta: Kencana Prenada Media Group, 2011.

Tu'aymah, Rushdi Ahmad. Ta 'lim al- 'Arabiyah li Ghayr An-Nathiqin biha: Manahijuhu wa Asalibuh. Maroko: ISESCO (Islamic Educational, Scientific and Cultural Organization), 1989.

Uno, Hamzah B. Orentasi Baru Dalam Psikologi Pembelajaran. Jakarta: Bumi Aksara, 2010. 